\title{
Lodo de reatores UASB: desaguamento através de protótipos de Leito de Drenagem
}

Sludge from UASB reactor: dewatering using prototypes of drainage bed

Fangos de reactores anaerobios: deshidratación usando prototipos de lecho de drenaje de lodos

Paulo Ricardo Santos Coimbra

Graduando em Engenharia Civil, UFSCar, Brasil paulorscoimbra@gmail.com

Cali Laguna Achon Professora Doutora do Departamento de Engenharia Civil, UFSCar, Brasil caliachon@gmail.com 


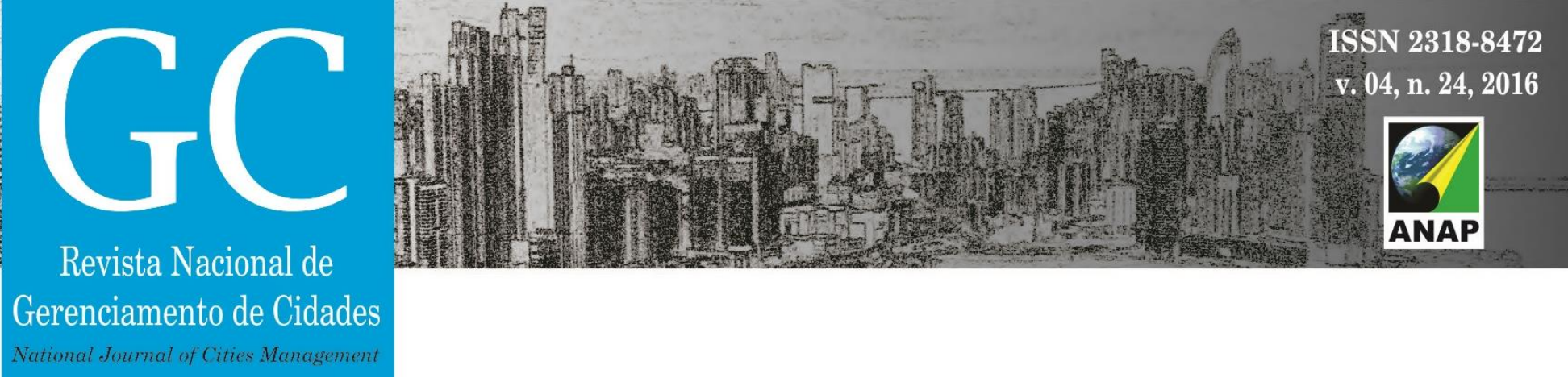

RESUMO

O tratamento de esgotos domésticos realizado pelas Estações de Tratamento de Esgoto (ETE) gera resíduos sólidos, dentre eles o lodo de esgoto. Este é gerado em grandes quantidades, possui gestão complexa, devendo ter destinação ambientalmente adequada. Deste modo, o Leito de Drenagem (LD) é um sistema natural de desaguamento de lodo, que reduz a quantidade de resíduo sem consumo de energia ou produtos químicos, através da remoção da água livre do lodo, facilitando sua gestão. Esse sistema possui comprovada eficiência para desaguamento de lodo de Estações de Tratamento de Água (ETA), o que justifica o estudo da aplicação do LD para lodo de ETE. Assim, este trabalho avalia o desaguamento de lodo de reator anaeróbio usando protótipos de LD, analisando a drenagem e a qualidade do drenado. Para tal foram realizados quatro ensaios, aplicando-se $20 \mathrm{~L}$ de lodo do reator anaeróbio nos protótipos de LD utilizando as mantas geotêxteis de $300 \mathrm{~g} / \mathrm{m}^{2}$ e $400 \mathrm{~g} / \mathrm{m}^{2}$ limpas e sujas. Durante os ensaios foram medidos vazão de drenagem, cor aparente, turbidez e pH do drenado. Os resultados demonstraram vazão inicial média de $1,21 \mathrm{~L} / \mathrm{min}$, sendo alcançado até $1,54 \mathrm{~L} / \mathrm{min}$ para a manta de $400 \mathrm{~g} / \mathrm{m}^{2}$ limpa. Após 120 minutos, o volume de lodo foi reduzido em $59 \%$ em média, atingindo $67 \%$ para manta de $300 \mathrm{~g} / \mathrm{m}^{2}$ suja. Após 60 minutos os ensaios apresentaram turbidez média de 33UNT e cor aparente média de 345uC, sendo que o $\mathrm{pH}$ variou entre 6,7 e 8,4.

PALAVRAS-CHAVE: Lodo de esgoto. Desaguamento. Leito de Drenagem.

\section{ABSTRACT}

The domestic sewage treatment made by Wastewater Treatment Plants (WWTP) generate solid waste, including the sewage sludge, generated in large quantities. It has a complex management and must be disposed correctly. Thus, the drainage bed (LD) is a natural sludge dewatering system, without power or chemicals consumption, which reduce the sludge volume. This system has proven its efficiency to sludge dewatering from drinking water treatment plants, which justifies the study of LD application for WWTP sludge. This work evaluates the anaerobic sludge dewatering using LD prototypes, analyzing drainage and the quality of percolated liquid. Four tests were done, applying $20 \mathrm{~L}$ of sludge from UASB reactor in LD prototypes, using clean and dirty geotextile of $300 \mathrm{~g} / \mathrm{m}^{2}$ and $400 \mathrm{~g} / \mathrm{m}^{2}$. During the tests were measured: drainage flow, apparent color, turbidity and $\mathrm{pH}$ of drained liquid. The results demonstrated an initial average flow of $1,21 \mathrm{~L} / \mathrm{min}$, reaching $1,54 \mathrm{~L} / \mathrm{min}$ for the prototype with clean geotextile of $400 \mathrm{~g} / \mathrm{m}^{2}$. After 120 minutes, the sludge volume was reduced by $59 \%$ on average, reaching $67 \%$ on dirty geotextile of $300 \mathrm{~g} / \mathrm{m}^{2}$. After 60 minutes, the tests showed 33NTU turbidity and 345uC color apparent, on average, and the $\mathrm{pH}$ ranged between 6.7 and 8.4.

KEYWORDS: Sewage sludge. Dewatering. Drainage bed.

\section{RESUMEN}

El tratamiento de las aguas residuales urbanas hecho por plantas de tratamiento de aguas servidas, genera residuos sólidos, como lodos de depuradoras. Ellos son producidos em gran cantidad, tienen una gestión compleja y deben tener destino correcto. Así, el lecho de drenaje (LD) es un sistema natural de deshidratación de fangos que no consume energía y productos químicos, disminuyendo el volumen de los lodos naturalmente. Esto tiene eficiencia demostrada para fangos originados en plantas de tratamiento de aguas potables, lo que justifica el estúdio de la aplicación de LD para los lodos de depuradora. En este trabajo se evalúa la deshidratación de lodo derivado de reactor anaerobio de flujo ascendente (UASB) utilizando lecho de drenage, analizando el drenaje y la calidad de la agua filtrada. A tal fin, se llevó a cabo cuatro ensayos, aplicando $20 \mathrm{~L}$ de fango en LD utilizando geosintéticos de 300 $\mathrm{g} / \mathrm{m}^{2}$ y $400 \mathrm{~g} / \mathrm{m}^{2}$ limpio y después de un uso. Durante los ensayos se midieron el flujo de agua, color aparente, turbidez y $\mathrm{pH}$. Los resultados demostraron una media de flujo inicial de 1,21L/min, logrado por 1,54L/min para el geosintético de $400 \mathrm{~g} / \mathrm{m}^{2}$ limpio. Después de 120 minutos, el volumen de lodo se redujo en un 59\% en promedio, alcanzando $67 \%$ com el geosintético de $300 \mathrm{~g} / \mathrm{m}^{2}$ sucio. Después de 60 minutos, los ensayos mostraron, em promedio, una turbidez de 33NTU y color aparente de $345 \mathrm{uC}$. El pH osciló entre 6,7 y 8,4.

PALABRAS CLAVE: Fangos de depuradoras. Deshidratación. Lecho de drenaje de lodos. 


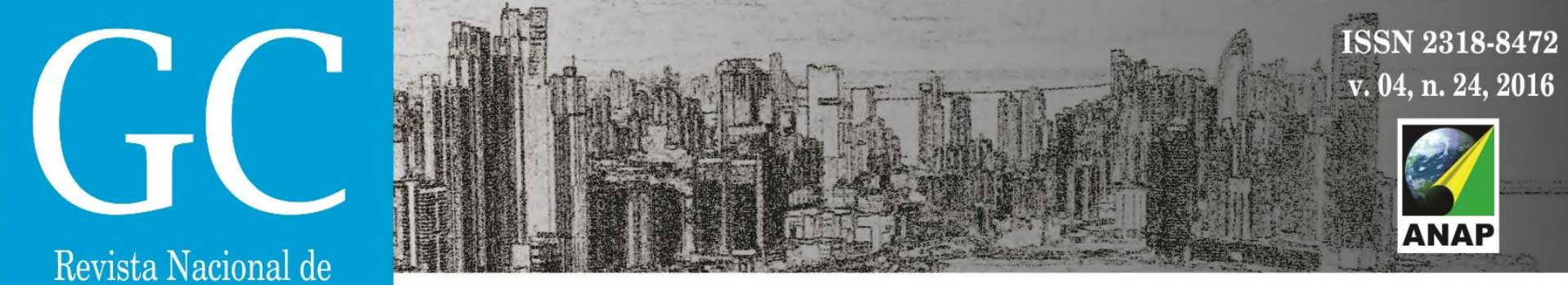

Gerenciamento de Cidades

\section{METODOLOGIA}

Os ensaios de desaguamento foram realizados no Laboratório de Saneamento da Universidade Federal de São Carlos entre os meses de abril e junho. O lodo foi coletado através de campanhas à ETE Monjolinho, localizada em São Carlos - SP, em recipientes com volume de amostras de $20 \mathrm{~L}$ de lodo dos reatores UASB da planta de tratamento.

Após as coletas, realizadas previamente ao início dos ensaios, foi realizada a caracterização das amostras do lodo bruto através da determinação do teor de sólidos totais e concentração de sólidos totais. Os procedimentos adotados seguiram métodos preconizados pela APHA/AWWA/WEF (2001) conforme apresentado no Quadro 1.

Quadro 1: Caracterização do lodo bruto e métodos utilizados.

\begin{tabular}{|c|c|c|c|}
\hline Material analisado & Parâmetro & Unidade & Procedimento \\
\hline \multirow{2}{*}{ Amostras de 20L de lodo bruto } & Teor de sólidos totais & $\%$ & $2540 \mathrm{G}$ \\
\cline { 2 - 4 } & Concentração de sólidos totais & $\mathrm{mg} / \mathrm{L}$ & $2540 \mathrm{~B}$ \\
\hline
\end{tabular}

Fonte: do Autor.

Buscou-se homogeneizar as amostras de $20 \mathrm{~L}$ de lodo, visando evitar a deposição dos sólidos no fundo dos recipientes, para tornar a caracterização mais representativa. Então, foram recolhidas amostras de $500 \mathrm{ml}$ de lodo bruto de cada ensaio para determinação dos parâmetros em triplicata. Os valores característicos dos parâmetros correspondem a média aritmética dos resultados obtidos.

Em seguida, os protótipos do Leito de Drenagem foram preparados. O equipamento possui cerca de $1 \mathrm{~m}$ de altura com área efetiva de fundo para drenagem pela manta geotêxtil de $0,35 \mathrm{~m} \times 0,35 \mathrm{~m}$. Sobre o leito de drenagem é disposta camada de brita lavada com cerca de $5 \mathrm{~cm}$ que serve como suporte e então colocada a manta geotêxtil para realização dos ensaios. $A$ Figura 1 apresenta o LD utilizado nos ensaios e a Figura 2 ilustra o protótipo com o geotêxtil aplicado e pronto para realização do ensaio. 
Ao longo da primeira hora de ensaio, as amostras recolhidas para determinação da vazão de drenagem foram analisadas quanto a qualidade do líquido drenado. Para tal, foram seguidos procedimentos determinados pela APHA/AWWA/WEF (2001) e analisadas as seguintes características: cor aparente, turbidez e pH, apresentadas pelo Quadro 2.

Quadro 2: Parâmetros de qualidade do líquido drenado e métodos utilizados.

\begin{tabular}{|c|c|c|c|}
\hline Material analisado & Parâmetro & Unidade & Procedimento \\
\hline \multirow{3}{*}{ Líquido drenado } & Cor aparente & UC & $2120 \mathrm{~B}$ \\
\cline { 2 - 4 } & Turbidez & UNT & $2130 \mathrm{~B}$ \\
\cline { 2 - 4 } & $\mathrm{pH}$ & & $4500-\mathrm{H}^{+} \mathrm{B}$ \\
\hline
\end{tabular}

Fonte: do Autor.

Passados 120 minutos do início do ensaio, foi considerado o término da fase de drenagem e após a secagem do lodo este foi removido do LD. A operação se deu manualmente com auxílio de luvas e também através de varrição com vassouras para remoção dos sólidos.

A brita foi novamente lavada e a manta considerada suja foi então recolocada no protótipo pronta para o início de um novo ensaio. É importante ressaltar que os experimentos com a manta suja (novo ciclo) não foram realizados no mesmo dia do término dos ensaios anteriores. A Figura 3 apresenta o aspecto da manta suja após remoção do lodo desaguado.

Figura 3: LD com manta geotêxtil suja após a remoção do lodo desaguado do ensaio anterior.

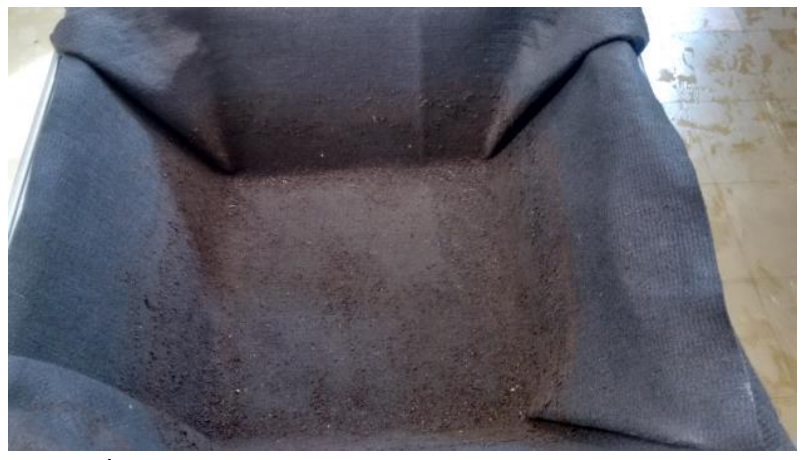

Fonte: do Autor.

Após esse procedimento repetiu-se a metodologia descrita anteriormente para o início dos ensaios C e D. Posteriormente a realização dos ensaios, os dados foram compilados e analisados em gráficos e tabelas.

\section{RESULTADOS}

As Tabelas 1 e 2 apresentam os resultados da caracterização do lodo bruto dos ensaios. 
Tabela 1: Teor de sólidos totais do lodo bruto dos ensaios.

\begin{tabular}{ccccc}
\hline \multirow{2}{*}{ Ensaios } & \multicolumn{4}{c}{ Teor de sólidos totais (\%) } \\
\cline { 2 - 5 } & Amostra 1 & Amostra 2 & Amostra 3 & Média \\
\hline Ensaio A & 4,36 & 4,33 & 4,22 & 4,30 \\
Ensaio B & 4,14 & 4,58 & 4,67 & 4,46 \\
Ensaio C & 2,51 & 2,88 & 3,22 & 2,87 \\
Ensaio D & 6,01 & 5,99 & 6,04 & 6,01 \\
\hline
\end{tabular}

Fonte: do Autor.

Tabela 2: Concentração de sólidos totais do lodo bruto dos ensaios.

\begin{tabular}{ccccc}
\hline \multirow{2}{*}{ Ensaios } & \multicolumn{4}{c}{ Concentração de sólidos totais (mg/L) } \\
\cline { 2 - 5 } & Amostra 1 & Amostra 2 & Amostra 3 & Média \\
\hline Ensaio A & 43.680 & 43.860 & 42.520 & 43.353 \\
Ensaio B & 41.210 & 45.520 & 46.620 & 44.450 \\
Ensaio C & 25.460 & 29.050 & 33.240 & 29.250 \\
Ensaio D & 60.050 & 60.240 & 60.750 & 60.347 \\
\hline
\end{tabular}

Fonte: do Autor.

As diferenças encontradas entre as condições iniciais do lodo bruto dos ensaios com as mantas limpas e sujas podem interferir na capacidade de desaguamento. De acordo com Mortara (2011), a concentração de sólidos inicial do lodo pode intervir nas taxas iniciais de drenagem. Segundo o autor, esse fator interfere na viscosidade do material e consequentemente no desaguamento do lodo.

Dessa forma, os parâmetros de drenagem analisados para o ensaio $D$ foram afetados pela maior concentração inicial do lodo utilizado com relação ao ensaio $B$, prejudicando a comparação entre a drenagem com a manta limpa e suja. Assim, a Tabela 3 apresenta resultados relativos à drenagem dos ensaios.

Tabela 3: Vazão de drenagem da água livre para os ensaios.

\begin{tabular}{ccccc}
\hline \multirow{2}{*}{$\begin{array}{c}\text { Tempo de ensaio } \\
\text { (min) }\end{array}$} & Ensaio A & Ensaio B & Ensaio C & Ensaio D \\
\cline { 2 - 5 } & 1318,68 & 1538,46 & 1349,53 & 618,17 \\
10 & 289,86 & 337,46 & 391,13 & 174,37 \\
30 & 93,31 & 106,84 & 69,67 & 75,89 \\
60 & 21,59 & 21,53 & 8,31 & 30,00 \\
120 & 4,00 & 2,90 & 2,67 & 8,71 \\
\hline
\end{tabular}

Fonte: do Autor.

A vazão inicial média dos ensaios foi de $1206 \mathrm{~mL} / \mathrm{min}$, sendo que os ensaios A, B e C apresentaram vazão superior a $1300 \mathrm{~mL} / \mathrm{min}$, um minuto após o início do ensaio, com a maior vazão de $1538 \mathrm{~mL} / \mathrm{min}$ no ensaio $B$. Passados 120 minutos, todos os ensaios possuíam vazão inferior a $10 \mathrm{~mL} / \mathrm{min}$, com destaque para o ensaio $C$, com a menor vazão final, de $2,67 \mathrm{~mL} / \mathrm{min}$. 


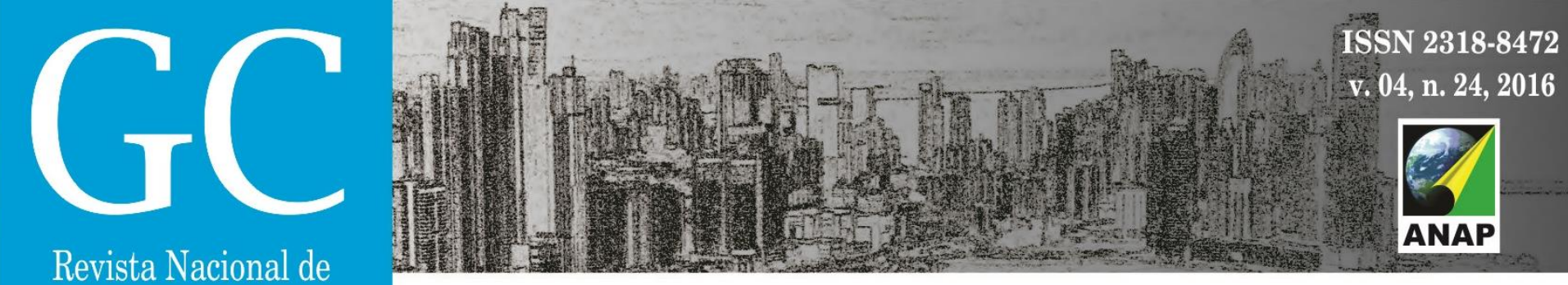

Gerenciamento de Cidades

Figura 5: Gráfico da variação do volume acumulado drenado $(\mathrm{mL})$ em função do tempo de ensaio.

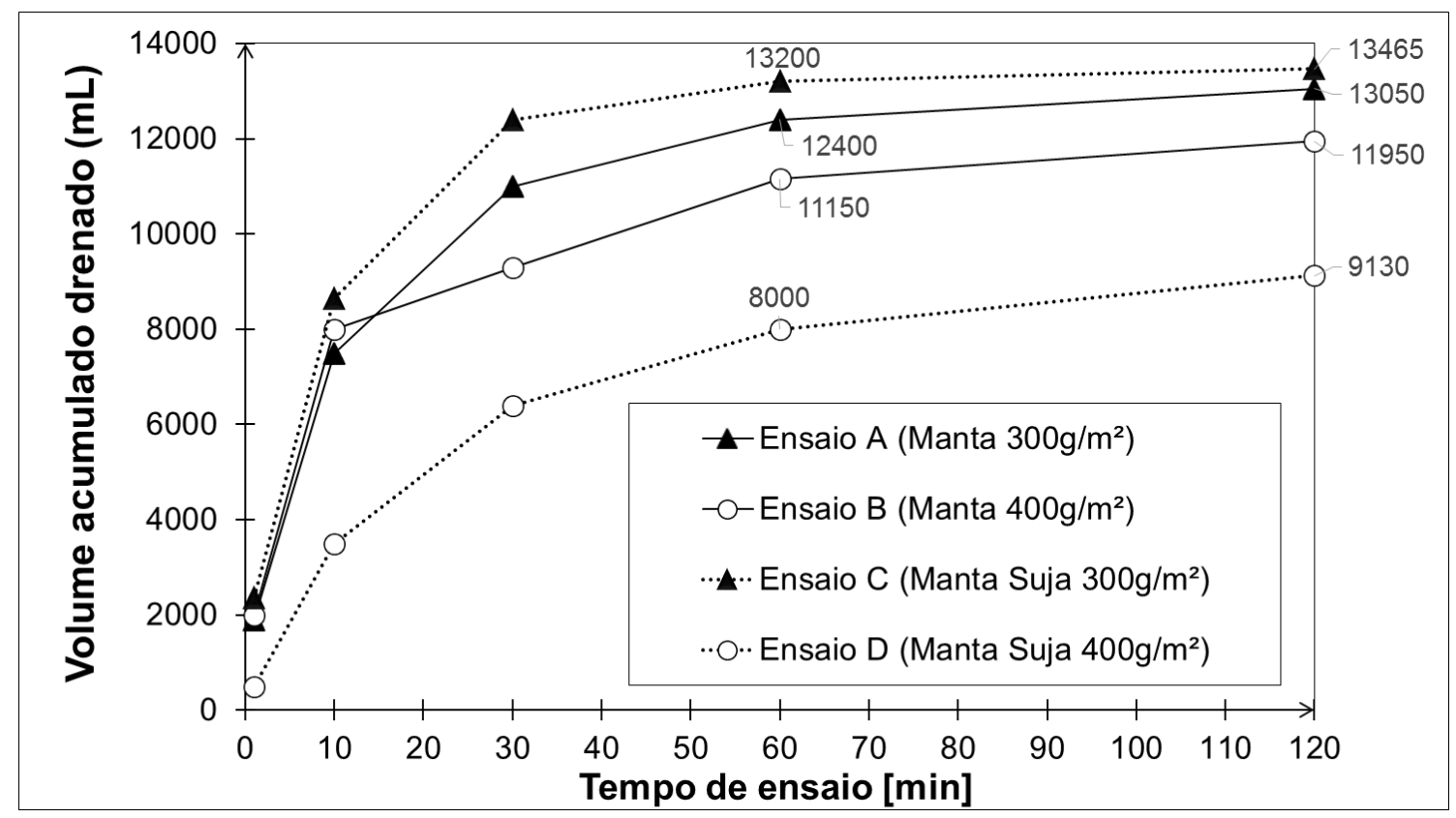

Fonte: do Autor.

Quanto à vazão de drenagem, percebe-se que os ensaios com melhores resultados das vazões também se destacaram quanto ao volume acumulado drenado. É importante notar que após 60 minutos, todos os ensaios drenaram mais de $8 \mathrm{~L}$, uma redução de $40 \%$, sendo que os ensaios $A, B$ e $C$ atingiram redução acima de $40 \%$ em apenas 30 minutos.

Após 120 minutos, os ensaios com as mantas com gramatura de $300 \mathrm{~g} / \mathrm{m}^{2}$ possuíam volume drenado superior a 13L, apresentando desempenho superior aos experimentos com manta de $400 \mathrm{~g} / \mathrm{m}^{2}$. De modo geral a Tabela 4 apresenta a redução de volume de lodo nos ensaios.

Tabela 4: Redução de volume de lodo (\%) nos experimentos.

\begin{tabular}{ccccc}
\hline \multirow{2}{*}{$\begin{array}{c}\text { Tempo de ensaio } \\
\text { (min) }\end{array}$} & Ensaio A & Ensaio B & Ensaio C & Ensaio D \\
\cline { 2 - 5 } & $9,50 \%$ & $10,00 \%$ & $11,75 \%$ & $2,50 \%$ \\
10 & $37,50 \%$ & $40,00 \%$ & $43,25 \%$ & $17,50 \%$ \\
30 & $55,00 \%$ & $46,50 \%$ & $62,00 \%$ & $32,00 \%$ \\
60 & $62,00 \%$ & $55,75 \%$ & $66,00 \%$ & $40,00 \%$ \\
120 & $65,25 \%$ & $59,75 \%$ & $67,33 \%$ & $45,65 \%$ \\
\hline
\end{tabular}

Assim, todos os ensaios apresentaram aptidão ao desaguamento com redução média de $59 \%$ do volume de lodo aplicado, sendo que os resultados obtidos com a manta de $300 \mathrm{~g} / \mathrm{m}^{2}$ destacaram-se em relação aos outros ensaios. O ensaio A (manta limpa) atingiu 65,25\% de redução de volume em 120 minutos e o Ensaio C (manta suja) 67,33\%. 
Entretanto, o ensaio $D$ teve desempenho abaixo dos demais com redução de volume de $45,65 \%$ em 120 minutos, provavelmente devido à concentração de sólidos totais superior aos demais ensaios.

Após a avaliação dos parâmetros de drenagem, deve-se observar também a qualidade do líquido drenado. Dessa forma, a Tabela 5 apresenta os resultados dos parâmetros de qualidade analisados.

Tabela 5: Parâmetros de qualidade do líquido drenado nos ensaios.

\begin{tabular}{|c|c|c|c|c|c|c|c|c|c|c|c|c|}
\hline \multirow{2}{*}{$\begin{array}{l}\text { Tempo } \\
\text { de } \\
\text { ensaio } \\
\text { (min) }\end{array}$} & \multicolumn{3}{|c|}{ Ensaio A } & \multicolumn{3}{|c|}{ Ensaio B } & \multicolumn{3}{|c|}{ Ensaio C } & \multicolumn{3}{|c|}{ Ensaio D } \\
\hline & $\mathrm{pH}$ & $\begin{array}{c}\text { Turbidez } \\
\text { (UNT) }\end{array}$ & $\begin{array}{l}\text { Cor } \\
\text { (uC) }\end{array}$ & $\mathrm{pH}$ & $\begin{array}{c}\text { Turbidez } \\
\text { (UNT) }\end{array}$ & $\begin{array}{l}\text { Cor } \\
\text { (uC) }\end{array}$ & pH & $\begin{array}{c}\text { Turbidez } \\
\text { (UNT) }\end{array}$ & $\begin{array}{l}\text { Cor } \\
\text { (uC) }\end{array}$ & $\mathrm{pH}$ & $\begin{array}{c}\text { Turbidez } \\
\text { (UNT) }\end{array}$ & $\begin{array}{l}\text { Cor } \\
\text { (uC) }\end{array}$ \\
\hline 1 & 6,85 & 242 & 705 & 6,87 & 171 & 1405 & 6,72 & 134 & 755 & 6,73 & 555 & 2730 \\
\hline 10 & 6,93 & 83 & 525 & 6,93 & 64 & 528 & 6,95 & 65 & 498 & 7,06 & 161 & 1105 \\
\hline 30 & 7,02 & 46 & 395 & 7,15 & 41 & 332 & 7,34 & 45 & 367 & 7,16 & 81 & 680 \\
\hline 60 & 7,23 & 31 & 279 & 7,51 & 34 & 323 & 7,82 & 34 & 294 & 8,33 & - & 484 \\
\hline
\end{tabular}

Fonte: do Autor.

Quanto a qualidade do drenado nota-se uma tendência de redução nos valores de turbidez e cor aparente das amostras com o passar do tempo. Após 30 minutos de ensaio encontraramse resultados semelhantes para turbidez e cor aparente nos ensaios A, B e C, com destaque para o primeiro ensaio, que apresentou após 60 minutos os menores valores dos parâmetros de qualidade com 279uC para cor aparente e 31UNT para turbidez.

Analisando os ensaios com a manta de $300 \mathrm{~g} / \mathrm{m}^{2}$ (ensaios A e C) nota-se que a turbidez do líquido drenado com uso da manta suja (ensaio $\mathrm{C}$ ) é bem inferior no início do ensaio, tendendo a se aproximar após 30 minutos. O mesmo observa-se quando são comparados os ensaios $\mathrm{A} e$ B, com uso das mantas de $300 \mathrm{~g} / \mathrm{m}^{2}$ e $400 \mathrm{~g} / \mathrm{m}^{2}$ limpas.

Com relação a cor aparente com uso da manta suja de $300 \mathrm{~g} / \mathrm{m}^{2}$ (ensaio $\mathrm{C}$ ), o valor é pouco superior no início do ensaio, reduz após 10 minutos, porém em 60 minutos atinge novamente valores superiores ao ensaio $\mathrm{A}$. Em contrapartida, quando comparamos os resultados dos ensaios A e B, a cor inicial do drenado para o ensaio B é o dobro. Contudo, os valores tendem a se aproximar após 10 minutos.

Os resultados da Tabela 5 podem ser considerados um indicativo de que a manta geotêxtil é mais efetiva na retenção de partículas em suspensão do que dissolvidas. Quanto aos resultados do líquido drenado para os ensaios com a manta de $400 \mathrm{~g} / \mathrm{m}^{2}$ (ensaios B e D), apesar de a turbidez e cor ser relativamente superior com o uso da manta suja (ensaio D) é difícil estabelecer comparações devido ao elevado teor de sólidos inicial do lodo bruto no ensaio $D$, de $6,01 \%$.

Por fim, os ensaios apresentaram pH semelhante no minuto inicial. Contudo, esse parâmetro não apresentou relações explicitas com os demais parâmetros, variando de 6,73 a 6,87 no início do ensaio. 


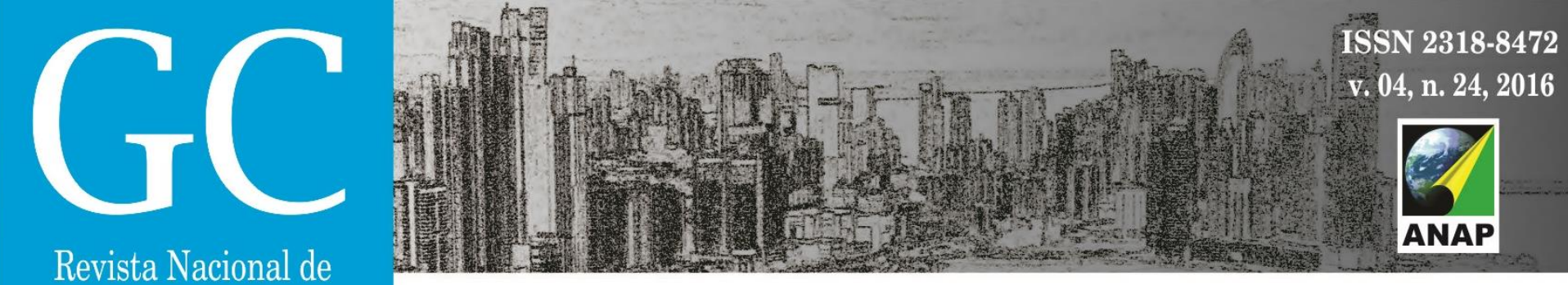

Gerenciamento de Cidades

\section{CONCLUSÃO}

As pesquisas relacionadas ao desaguamento de lodo de ETE em Leito de Drenagem são poucas quando comparadas ao lodo de ETA. Contudo, os resultados encontrados para o desaguamento de lodo de ETA em LD demonstram a eficiência e aplicabilidade deste sistema natural de redução de volume deste resíduo, sugerindo os estudos de uso do LD para lodo de ETE também.

Em relação a drenagem a vazão inicial média foi semelhante com exceção do ensaio com manta geotêxtil suja de $400 \mathrm{~g} / \mathrm{m}^{2}$, que pode também ter sido influenciado pelo elevado teor de sólidos totais do lodo bruto. As vazões foram reduzindo, tendendo ao fim da drenagem em até 120 minutos, quando os ensaios alcançaram redução de $45,65 \%$ até $67,33 \%$ em termos volumétricos. A manta de $300 \mathrm{~g} / \mathrm{m}^{2}$ se destacou alcançando após 120 minutos os dois maiores valores de redução com a manta limpa e suja.

Quanto à qualidade, constatou-se tendência de redução nos parâmetros de cor aparente e turbidez, sendo que valores semelhantes entre os ensaios foram encontrados após 30 minutos, com exceção do ensaio com a manta geotêxtil de $400 \mathrm{~g} / \mathrm{m}^{2}$ suja. O uso da manta de $300 \mathrm{~g} / \mathrm{m}^{2}$ suja reduziu os valores de turbidez inicial, porém o mesmo não ocorreu para a cor aparente, tendendo a se igualar após 30 minutos.

Por fim notou-se que a concentração de sólidos totais do lodo bruto pode ter influenciado tanto nos parâmetros de drenagem como na qualidade do drenado, sendo necessários estudos mais detalhados para avaliar seu efeito no desaguamento.

\section{AGRADECIMENTO}

Os autores agradecem ao Conselho Nacional de Desenvolvimento Científico e Tecnológico (CNPq) pelo apoio financeiro para a realização desta pesquisa (Processo $n^{\circ}$. 123356/2015-6).

\section{REFERÊNCIAS BIBLIOGRÁFICAS}

ACHON, C.L.; BARROSO, M. M; CORDEIRO, J.S. Leito de Drenagem: sistema natural para redução de volume de lodo de estação de tratamento de água. Revista Engenharia Sanitária e ambiental. Rio de Janeiro. v. 13, n. 1, p. 54-62, jan/mar. 2008. Disponível em: <http://dx.doi.org/10.1590/S1413-41522008000100008>. Acesso em: set. 2016.

APHA - AMERICAN PUBLIC HEALTH ASSOCIATION. Standard Methods for The Examination of Water and Wastewater. 20.ed. Washington DC, USA. 2001.

ASSOCIAÇÃO BRASILEIRA DE NORMAS TÉCNICAS. NBR 12209: Elaboração de projetos hidráulico-sanitários de estações de tratamento de esgotos sanitários, Rio de Janeiro, 2011. 53 p.

BARROSO, M. M. Influência das micro e macropropriedades dos lodos de estações de tratamento de águas no desaguamento por Leito de Drenagem. 2007. 249 p. Tese (Doutorado) - Escola de Engenharia de São Carlos, Universidade de São Paulo, São Carlos, 2007. 


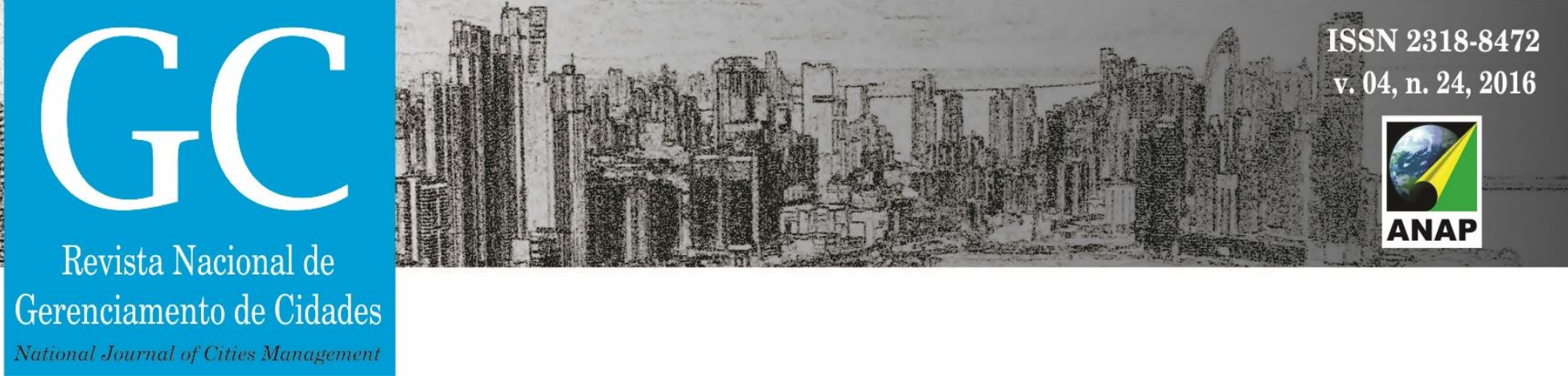

BRASIL. Resolução CONAMA No 357 de 17 de março de 2005. Dispõe sobre a classificação dos corpos de água e diretrizes ambientais para o seu enquadramento, bem como estabelece as condições e padrões de lançamento de efluentes, e dá outras providências. Ministério do Meio Ambiente, Brasil, Conselho Nacional do Meio Ambiente, 2005, 27 p.

BRASIL. Resolução CONAMA N.o 375 de 29 de agosto de 2006. Define critérios e procedimentos para uso agrícola de lodos de esgoto gerados em estações de tratamento de esgoto sanitário e seus produtos derivados, e dá outras providências. Ministério do Meio Ambiente, Conselho Nacional do Meio Ambiente, 2006a, 32 p.

BRASIL. Resolução CONAMA N.o 380 de 31 de outubro de 2006. Retifica a Resolução CONAMA no 375/2006 Define critérios e procedimentos para uso agrícola de lodos de esgoto gerados em estações de tratamento de esgoto sanitário e seus produtos derivados, e dá outras providências. Ministério do Meio Ambiente, Conselho Nacional do Meio Ambiente, 2006b, 2 p.

BRASIL. Lei № 12.305 de 02 de agosto de 2010. Política Nacional de Resíduos Sólidos. Congresso Nacional, Brasília, DF, 2010.

BRASIL. Resolução CONAMA No 430 de 13 de maio de 2011. Dispõe sobre as condições e padrões de lançamento de efluentes, complementa e altera a Resolução № 357, de 17 de março de 2005, do Conselho Nacional do Meio Ambiente - CONAMA. Ministério do Meio Ambiente, Brasil, Conselho Nacional do Meio Ambiente, 2011.

BRASIL. MINISTÉRIO DAS CIDADES, SECRETARIA NACIONAL DE SANEAMENTO AMBIENTAL. Sistema Nacional de Informações sobre Saneamento: Diagnóstico dos Serviços de Água e Esgotos - 2014. Brasília: SNSA/MCIDADES, 2016, 212 p.: il.

CORDEIRO, J. S. Processamento de lodos de Estações de Tratamento de Água (ETA's). In: ANDREOLLI, C. V. (Coord). Resíduos sólidos do saneamento: processamento, reciclagem e disposição final. Capítulo 9. Rio de Janeiro: ABES, 2001. 282 p. (Projeto PROSAB).

CORDEIRO, J.S., REIS, R. F.; ACHON, C.L.; BARROSO, M. M. Evolução dos Leitos de Drenagem (LD) no Brasil - uma década de avanços. In: XXXIV Congresso Interamericano de Engenharia Sanitária e Ambiental (AIDIS), Anais. Monterrey - México, 2 a 6 novembro de 2014, cód. 332-T8-Cordeiro-Brasil-1, 8 p.

FONTANA, A.O. Sistema de leito de drenagem e sedimentador como solução para redução de volume de lodo de decantadores e reuso de água de lavagem de filtros - estudo de caso - ETA Cardoso. 2004, 161 p. Dissertação (Mestrado). Universidade Federal de São Carlos/UFSCar. São Carlos, 2004.

KURODA, E. K.; SILVEIRA, C.; MACEDO, J. G.; LIMA, M. S. P.; KAWAHIGASHI, F.; BATISTA, A. D.; SILVA, S. M. C. P.; FERNANDES, F. Drenagem/secagem de lodo de decantadores de ETA em manta geotêxtil. Revista DAE, n. 194, p.2434, jan/abr. 2013. Disponível em: <http://dx.doi.org/10.4322/dae.2014.002>. Acesso em: set. 2016.

MINISTÉRIO DAS CIDADES (Org). Lodo gerado durante o tratamento de água e esgoto. Transversal: guia do profissional em treinamento: nível 2. Secretaria Nacional de Saneamento Ambiental, Brasília, 2008, 90 p.

MORTARA, F. C. Utilização de leitos de drenagem no desaguamento de lodos anaeróbios. 2011. 241p. Dissertação (Mestrado). Departamento de Engenharia Hidráulica e Sanitária, Escola Politécnica da Universidade de São Paulo, São Paulo, 2011.

REIS, R.F. Estudo de Influência de Cobertura Plástica na Remoção de Água de Lodos de Estações de Tratamento de Água em Leitos de Drenagem. 2011. 131p. Dissertação (Mestrado). Departamento de Engenharia Civil, Universidade Federal de São Carlos, São Carlos, 2011.

SÃO PAULO (Estado). Secretaria do Meio Ambiente. Companhia Ambiental do Estado de São Paulo - CETESB. Plano de Resíduos Sólidos do Estado de São Paulo. 1a ed. - São Paulo: SMA, 2014, 350 p. 
Revista Nacional de

Gerenciamento de Cidades

National Journal of Cities Management

SÃO PAULO (Estado). Secretaria do Meio Ambiente. Companhia Ambiental do Estado de São Paulo - CETESB. Qualidade das águas superficiais no estado de São Paulo 2015. 1ạ ed. - São Paulo: CETESB, 2016, 562 p.

SILVEIRA, C. Desaguamento de lodo de estações de tratamento de águas por leito de drenagem/secagem com manta geotêxtil. 2012. 137 p. Dissertação (Mestrado). Centro de Tecnologia e Urbanismo, Universidade Estadual de Londrina, Londrina, 2012.

VON SPERLING, M. Introdução à qualidade das águas e ao tratamento de esgotos. 3. Ed. Belo Horizonte: Departamento de Engenharia Sanitária e Ambiental; Universidade Federal de Minas Gerais, 2005, 452 p. 